\title{
Interview
}

\section{An interview with Dr Carmen Herrero, an expert in film and language education}

\section{Una entrevista con Dra. Carmen Herrero, experta en pedagogía de lengua y cine}

\author{
Marta F. Suarez \\ Manchester Metropolitan University
}

(Text received 20 October 2019; accepted 20 October 2019)

DOI: https://doi.org/10.5565/rev/jt13.837

\begin{abstract}
Carmen Herrero is a principal lecturer and Spanish section lead in the Department of Languages, Information and Communication at Manchester Metropolitan University. She is the director of FLAME (Research Centre for Film, Languages and Media Education) (https:// www2.mmu.ac.uk/languages/flame/) and co-founder of the Film in Language Teaching Association (www. lta.org.uk). She has been part of the European project Communication for Mobile and Virtual Work (CoMoViWo) (http://www.comoviwo.eu). Her research focuses on language and media pedagogy (the use of language and audiovisual media to enhance language learning and teaching) and contemporary Spanish in language and media. Recent publications include an edited volume on 'Using film and media in the language classroom: Reflections on researchled teaching' (2019), a chapter on 'From new literacies to transmedia literacies: New approaches to transmedia and languages pedagogy project' (2019), another one on 'Medios audiovisuales' for The Routledge handbook of Spanish language teaching: Metodologías, contextos y recursos para la enseñanza del español L2' (2018); and 'Film in Language Teaching Association (FILTA): A multilingual community of practice' for the English Language Teaching Journal (2016). Her current line of research explores the use of transmedia practices in language learning and teaching as part of the AHRCfunded OWRI programme Cross-Language Dynamics: Reshaping Community.
\end{abstract}

\section{Interview}

Interviewer: You have been working with videos in the classroom for almost two decades. Why do you think it is so important to work with videos in the language and/or literature classroom?

Herrero: Well, I think activities based on film, video and audiovisual media have been used for many years in the language classroom. However, in the current digital era in which we live, 
we obviously need to consider how new technologies have changed the way we communicate, we learn, and we work. Nowadays, communication is multimodal. Texts (including videos) are not limited to the language-based mode. Films, for example, integrate multiple modes for meaning-making (linguistic and visual codes, sound and gestures) that are socially constructed. Therefore, videos are an ideal tool for bringing multimodal texts most prominently into the language curriculum. Also, the rapid changes in today's media landscape are affecting the way popular culture is consumed, on how culture is impacting technology and, vice versa, how technology is impacting culture. From my point of view, using videos in the language and literature classroom engage with young people's experiences of popular culture. Just because they are associated with entertainment does not mean that videos don't have an educational value. I find it particularly interesting to consider trends in the learning practices of secondary and higher education learners. It is clear that innovative education models (flipped learning, blending learning and distance learning) rely on the use of educational videos and other social mediarelated tools to support the learning-teaching processes and assessments. A recent study, which explores how technology and video enhance the higher education student learning experience in the UK, states that video has become the preferred learning medium for the majority of students. Students use online video platforms (i.e. YouTube or Vimeo) to learn new skills or to inspire independent study and they prefer learning via audiovisual materials to books. If we want students to learn a second language, we would expect them to do it in a similar way in which they acquire new knowledge and improve their skills. So, yes, it is not only an important but an indispensable tool for teaching languages to support learning and assessment of students' competences.

Interviewer: Is there a specific kind of video that you would recommend, or do you think any video can be used in the classroom?

Herrero: I think that the big lesson that I have learned from all these years teaching using films is that the learner's motivation is crucial. Rather than thinking about the type of films I like, I consider how a video or film connects with students' experiences and interests. It is also important to take into consideration how the new technologies have opened up new possibilities, bringing new stylistic conventions. I think we can find inspiration in how we consume and create online video, and the new video genres, from vlogs to how-to tutorials videos. In my opinion, among all the audiovisual media that we can turn to when learning and teaching culture 
in an L2 class, films stands out for their artistic value, affective load and multisensory wealth. Watching films is an emotional and emotion-generating experience, linked to empathy and identification with the characters, which contributes to the understanding of the narrative and the interpretation of the ideological content of the films. Above all, it is a motivating medium that, like television, provokes a sensory stimulus and an emotional response. The aesthetic component of films has an extraordinary influence on the emotional state of the viewer and is an ideal instrument to develop students' visual literacy and critical thinking. Film has contributed to giving visibility to certain marginalized or excluded groups of hegemonic representation (the LGBT community, indigenous groups, women, immigrants, etc.). The television format is certainly successful in motivating students to watch more media in the original language. I know that my students watch La casa de papel (Money Heist), Las chicas del cable (Cable Girls), Élite (Elite) or El ministerio del tiempo (The Ministry of Time). I am also very much in favour of using short films, including short films without dialogue. In fact, I think there are lots of advantages in the use of shortest formats such as video clips, trailers, teasers, advertising commercial and flash fiction. So, with careful preparation and selection any video can be used in the language classroom.

Interviewer: What are the advantages of working with videos that relate to transmedia content?

Herrero: Transmedia content is normally associated with transmedia storytelling, namely, using multiple media platforms to tell a narrative as a cumulative process. According to Henry Jenkins, transmedia narratives are "stories told through a combination of means", for example a comic, video game, film or a novel. Each story complements the other and, at the same time, enriches the audience experience making them more involved. In the current era of "convergence", transmedia is linked to media franchises (Star Wars, Star Trek, and Harry Potter, for example). However, the main principles of storytelling and techniques can be applied to education to make curricular content more engaging. Focusing on pedagogical applications of transmedia, I think there are many advantages but this is an area that is just starting to be developed both in terms of research and teaching practice. There is no doubt that, in recent years, there has been growing interest in Transmedia in Education, for example the Transmedia Literacy Project. This was also the focus, but applied to language learning and teaching, of the international conference that the research group FLAME, organised in June at the Manchester Metropolitan University, supported by the AHRC/ OWRI Cross-Language Dynamics. So, in 
education, videos will be one of the components of transmedia storytelling that can promote different types of literacies (critical, digital, game, media, and multimodal literacy). Another advantage is the fact that activities based on transmedia storytelling can make the classes more relevant to the students by making learning more active, participatory and collaborative. I think transmedia is linked to gamification so a key issue is to think about how we, teachers, can adopt a process-driven approach to learning a language by integrating activities linked to entertainment; and how we can expand the narrative of videos to other media formats. So, this is a work in progress but a clear trend in language teaching.

Interviewer: Some people might frown upon using musical videos in the classroom, what is your view on this? What can these videos offer?

Herrero: I think music videos offer many options for the language classroom because they are accessible on the Internet and they allow to connect with students' tastes and preferences. It is easy to list music videos from major popular artists that we could work with, like Ed Sheeran, Taylor Swift, Katy Perry, as well as Luis Fonsi and Daddy Yankee and Rosalia. For example, in the UK the popularity of Korean language is linked to the boy band BTS. Music videos are ideal for developing media literacy because of the audiovisual elements that usually go with the songs. We can use not only professional videos but also videos created by YouTubers that combine different elements (visual graphics and dance) or remixing songs. In fact, music videos are often an ideal model for encouraging students' video creation. Very often, we tend to consider videos in terms of linguistic and visual content, overlooking the power that music and sound have to enhance the viewing experience. I can think as well as the power of popular singers and groups for inspiring young learners to study languages, to learn the lyrics, to expand their vocabulary, aural skills, pronunciation, and cultural knowledge. In the case of film, neuroscience research has reported that emotions aroused by film and music are intimately tied to cognition. Furthermore, many scholars argue that film music contributes to the perception and understanding of the film narrative and to experience a sense of empathy with movie characters. Starting from the premise that music can enhance cognitive performance in foreign language learning, one of my forthcoming articles explores the theoretical and pedagogical implications and applications of the use of film music to language learning and teaching. I argue based on an interdisciplinary approach, that music film can also enhance empathy and, therefore, is a particularly useful tool for developing students' intercultural communicative competence. 
Interviewer: Are there any obstacles to work these materials in the classroom?

Herrero: Yes, of course. Through the Film in Language Teaching Association (FILTA), I am in direct contact with language teachers around the world so I am quite familiar with some of the barriers that language teachers encounter when thinking about how to embed videos in their classes. Digital technologies facilitate working with videos but also pose legal, pedagogical and technical challenges. In fact, one of the aims of the research project in which I am currently involved, the Teacher Training project -funded by the AHRC/ OWRI Cross-Language Dynamics-, is to identify language teachers' concerns and training needs in this field. The feedback provided by the teachers is related to language skills, for example how to use short films or film clips to teach grammar or develop language skills. There is a need for guidance on using videos for developing critical skills, and guidance on embedding critical thinking and other skills. Other training requests were connected to the role of audiovisual media to introduce cultural themes. Many teachers would also like to be trained in film and media analysis. One of the aspects that we have identified is the importance of facilitating resources. Teachers do not have too much time to prepare activities. This is why the free resources available via the FILTA (http://www.filta.org.uk) and the Transmedia in Education (http://www.transmediaineducation.com) websites are particularly valued by language educators. In addition to methodology and guidance, I think it is important to reassure teachers of the educational value of videos by learning from other teachers practices. One of the reasons for the growth of FILTA is the networking opportunities that allow learning from other teachers practices. One more issue that is worth mentioning is that with so many videos available today, the task of watching and selecting videos can be overwhelming.

Interviewer: What advice would you give to a teacher wanting to introduce audiovisual material in the classroom?

Herrero: Given the versatility of the applications of audiovisual media in the language classroom, the first issue to consider is why you want to use this material and for what purpose. An exploitation task based on audiovisual media requires planning and execution according to the learning objectives and curricular content. In the teacher courses and workshops that I offer to language educators, I suggest some guidelines that can help them to get the most out of the 
audiovisual media in their classes. Audiovisual material can be integrated into curriculum design from different perspectives. First, I advise consideration of the functions of videos in the language classes. They can support and develop language content and written and aural skills. As I have mentioned, they are ideal tools to develop cultural knowledge and develop intercultural competencies, as well as to media literacy. For example, in the event that I do in collaboration with the cinema HOME, the activities include the analysis of genre conventions and directors' style, while encouraging thematic discussions - for example, on political contexts, historical periods and gender. Video can also be introduced as a cultural activity. Out-of-school events can be part of this category. For example, every year I organise a film festival, Beyond Babel, open to students, staff and open to any person who is interested in multilingual films. Videos and films can be included as study material in a unit or module or monographic course. It is possible to include audiovisual material and films as part of a course on literature or history. The second aspect is the criteria for the selection of audiovisual materials, for example considering the age of the learners, the length of the video, the genre, etc. The next step is to think about sequencing resources. Finally, there is a growing number of students who record their own video content and we should tap into the knowledge and skills that they are already familiar with. I think there is growing trend related to making moving images as part of formative and summative assessments. For those teachers who are interested in finding ideas and inspiration, I would like to invite them to join the Film in Language Teaching Association (with free membership!), as well as to visit the Transmedia in Education website.

\begin{abstract}
Author's information
Marta F Suarez is a final-year PhD candidate at Liverpool John Moores University and Lecturer of Spanish and Latin American Studies at Manchester Metropolitan University. She has lectured across different universities on modules on film theory, screenwriting, intersectionality (race/gender), genre and nation. Her PhD thesis explores the portrayal of immigration in contemporary Spanish film, in which she discusses issues of globalisation, (post)colonialism and national identity. Her recent and forthcoming publications approach intersectionality in a wide variety of screen media, from the Spanish films at the core of her $\mathrm{PhD}$ thesis to TV narratives and dystopian worlds, particularly on The Walking Dead. She is a PGR representative and EC member of BAFTSS (British Association of Film, Television and Screen Studies), as well as the commentaries editor for Open Screens.

E-mail: M.Suarez@mmu.ac.uk
\end{abstract}

To cite this article:

Suarez, M. F. (2019). An interview with Dr Carmen Herrero, an expert in film and language education. Bellaterra Journal of Teaching \& Learning Language \& Literature 12(4), 113-118. DOI: https://doi.org/10.5565/rev/jt13.837

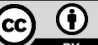

